\title{
A assistência de enfermagem diante de pacientes com Transtorno do Espectro Autista (TEA): uma revisão da literatura
}

Compreender as complicações e alterações que envolvem principalmente os cuidados que se deve ter com a criança portadora de autismo, contribui de forma positiva no cuidado e atenua implicações e sofrimentos ao núcleo familiar em especifico o cuidar. Neste contexto o profissional enfermeiro tem papel importante frente a este cuidado, uma vez que este profissional avalia e traça estratégias que possibilitem minimizar impactos negativos do autismo a estas famílias. Frente ao exposto a presente pesquisa teve como objetivo geral identificar como é realizada a assistência de enfermagem aos pacientes portadores de TEA e seus familiares de acordo com a literatura científica já publicada. A presente pesquisa trata-se de um estudo descritivo do tipo revisão bibliográfica integrativa nas bases de dados eletrônicas referente a assistência de enfermagem frente ao portador de TEA e seus familiares, publicados nos últimos 20 anos.

Palavras-chave: Transtorno do espectro autista; Assistência de enfermagem; Familiares.

\section{Nursing assistance for patients with Autistic Spectrum Disorder (ASD): a literature review}

\begin{abstract}
Understanding the complications and changes that mainly involve the care that should be taken with the child with autism, contributes positively to the care and mitigates implications and suffering to the family nucleus in specific care. In this context, the professional nurse plays an important role in this care, since this professional evaluates and outlines strategies that make it possible to minimize the negative impacts of autism on these families. In view of the above, the present research had the general objective of identifying how nursing care is provided to patients with ASD and their families, according to the scientific literature already published. The present research is a descriptive study of the type integrative bibliographic review in the electronic databases referring to the nursing assistance facing the patient with ASD and their family members, published in the last 20 years.
\end{abstract}

Keywords: Autism spectrum disorder; Nursing care; Family members.

Topic: Enfermagem Psiquiátrica

Reviewed anonymously in the process of blind peer.
Received: $19 / 10 / 2020$

Approved: 20/01/2021
Samira Hellen Greco Mendes Silva (i)

Universidade do Estado de Mato Grosso, Brasil

http://lattes.cnpq.br/4152921039543453

http://orcid.org/0000-0003-1525-8779

samiragreco9@gmail.com

Amaly Vidal Aziz (D)

Universidade do Estado de Mato Grosso, Brasil

http://lattes.cnpq.br/7759234030405025

http://orcid.org/0000-0002-8871-1258

amaly.cac@gmail.com

Noely Machado Viera (D)

Universidade do Estado de Mato Grosso, Brasil

http://lattes.cnpq.br/4720289798017017

http://orcid.org/0000-0002-3705-7006

noelyenf@outlook.com
Mariana Lenina Menezes Aleixo (iD)

Universidade do Estado de Mato Grosso, Brasil

http://lattes.cnpq.br/2641517259797926

http://orcid.org/0000-0002-9363-2423

marianalenina@gmail.com

Bianca Teshima de Alencar (iD

Universidade do Estado de Mato Grosso, Brasil

http://lattes.cnpq.br/9101535074774508

http://orcid.org/0000-0001-6812-3494

biancateshima@gmail.com
Referencing this:

SILVA, S. H. G. M.; AZIZ, A. V.; VIEIRA, N. M.; ALEIXO, M. L. M.;

ALENCAR, B. T.. A assistência de enfermagem diante de pacientes com Transtorno do Espectro Autista (TEA): uma revisão da literatura. Scire Salutis, v.11, n.1, p.36-45, 2021. DOI:

http://doi.org/10.6008/CBPC2236-9600.2021.001.0004 


\section{INTRODUÇÃO}

O transtorno do espectro autista (TEA) é caracterizado como uma síndrome comportamental complexa, que atinge principalmente o desenvolvimento sociocomunicativo e afetivo, como também a presença de comportamentos estereotipados e de um repertório restrito de interesses e atividades (ZANON et al., 2014). É uma condição que tem início precoce, aos três anos, sendo que antes disso os médicos apresentam dificuldades para concluir o diagnóstico. $O$ autismo é descoberto pela família com a convivência, de uma forma progressiva e dolorosa e normalmente pela ausência do desenvolvimento normal. Toda família é atingida pela notícia, passam pela fase do alarme, do estresse, da angústia, da rejeição e da revolta, que costumam ocorrer logo após a notícia. O primeiro filho deficiente faz com que os pais não queiram ter mais filhos, pelo medo de que o próximo possa ser portador do mesmo transtorno (SERRA, 2010).

Estima-se que exista mais de 2 milhões de portadores do autismo no Brasil, e mesmo com muitos casos, ainda é complicado encontrar um tratamento adequado. Não existe um exame genético que afirme a incidência da síndrome, e não se sabe exatamente o que a causa, muitos dizem que a gestante quando faz uso em excesso de ácido fólico durante toda a gravidez, pode acometer o feto a ter a síndrome, mutação genética, ou até mesmo a influência do ambiente, mas nada com precisão ou certeza. Geralmente os pais começam a identificar comportamentos "anormais" em seus filhos, que seria mais ou menos entre os 3 anos de idade, que é onde a criança começa a desenvolver mais contato social, interação e linguagem, assim, procuram um especialista para que o diagnóstico seja feito. Depois da descoberta do diagnóstico do autismo, o portador e seus familiares se deparam com mais uma barreia pela frente: busca pelo tratamento adequado e os demais atendimentos como saúde, educação e assistência social (SOUZA et al., 2019).

Compreender as complicações e alterações que envolvem principalmente os cuidados que se deve ter com a criança portadora de autismo, contribui de forma positiva no cuidado e atenua implicações e sofrimentos ao núcleo familiar em especifico o cuidar. Neste contexto o profissional enfermeiro tem papel importante neste processo uma vez que este está diretamente ligado ao cuidado, avaliando, e traçando estratégias que possibilitem minimizar impactos negativos do autismo a estas famílias (NOGUEIRA et al., 2011).

Frente ao exposto a presente pesquisa teve como objetivo geral identificar como é realizada a assistência de enfermagem aos pacientes portadores de TEA e seus familiares de acordo com a literatura científica já publicada.

\section{METODOLOGIA}

\section{Desenho de estudo}

A presente pesquisa trata-se de um estudo descritivo do tipo revisão bibliográfica integrativa nas bases de dados eletrônicas referente a assistência de enfermagem frente ao portador de TEA e seus familiares, publicados nos últimos 20 anos. 


\section{Bases de dados eletrônicas}

A pesquisa bibliográfica será conduzida nas seguintes bases de dados eletrônicas: (1) Scientific Electronic Library Online - SciELO; (2) Literatura Latino-americana e do Caribe em Ciências da Saúde - LILACS; e (3) Google Acadêmico.

As buscas foram conduzidas através de descritores catalogados no Descritor em Ciências da Saúde DeCS. Será utilizado o operador booleano 'OR', além da utilização das aspas a fim de facilitar a busca aos manuscritos.

A combinação de termos que utilizados juntos ou separados nas respectivas bases de dados (SciELO, Google Acadêmico, LILACS) foram: Autismo Infantil, Autismo e a família, Transtorno do Espectro autista, Enfermagem.

\section{Critérios de inclusão e exclusão}

Foram selecionados para presente pesquisa estudos que atendessem aos seguintes critérios:

Critérios de inclusão: artigos disponíveis na íntegra que correspondem ao tema abordado, artigos publicados nos idiomas português, inglês e espanhol, pesquisas desenvolvidas com crianças de 18 meses a 10 anos que não sejam do tipo revisão bibliográfica.

Critérios de exclusão: artigos duplicados ou repetidos nas bases de dados.

\section{Seleção e análise das publicações}

Inicialmente, foi realizado o levantamento de todos os artigos encontrados com os uni termos propostos e dentro dos limites apresentados nos títulos e palavras descritoras. Em seguida, retirados trabalhos recuperados em mais de uma base de dados (duplicatas). Após esta triagem, realizou-se a leitura dos resumos de todos os artigos restantes, para a seleção daqueles que seriam lidos em sua forma completa. Após a leitura dos artigos completos, apenas foram selecionados os que se adequarem aos critérios de inclusão e exclusão. As informações extraídas dos artigos foram filtradas e expostas em forma de tabelas.

\section{RESULTADOS}

Foram encontradas 73.794 publicações utilizando os descritores: Autismo Infantil, Autismo e a família, Transtorno do Espectro autista, Enfermagem, sendo 21.654 publicações na SciELO, 41.140 na LILACS e 11.000 publicações no Google Acadêmico. Após primeira revisão foram selecionadas 28 publicações. Com a aplicação dos critérios de inclusão e exclusão das 28 publicações selecionadas, 14 foram selecionadas para análise (Figura 1).

Conforme observado na tabela 1, quanto ao período de publicação observou-se maior frequência nos anos de 2018 e 2019. São Paulo aparece como a região que mais foram publicados esses artigos (4 artigos), o principal tipo de estudo foi o de cunho exploratório, qualitativo em 13 artigos, e apenas 1 de cunho transversal. Os principais achados de enfermagem foram à identificação de alterações disfuncionais, a 
implementação da SAE e elaboração de intervenções e diagnósticos de enfermagem voltados para a síndrome, os cuidados como alimentação, higiene pessoal e troca de fraldas, o acompanhamento desse portador de TEA e o auxílio do profissional enfermeiro aos familiares, como, apoio e informações.

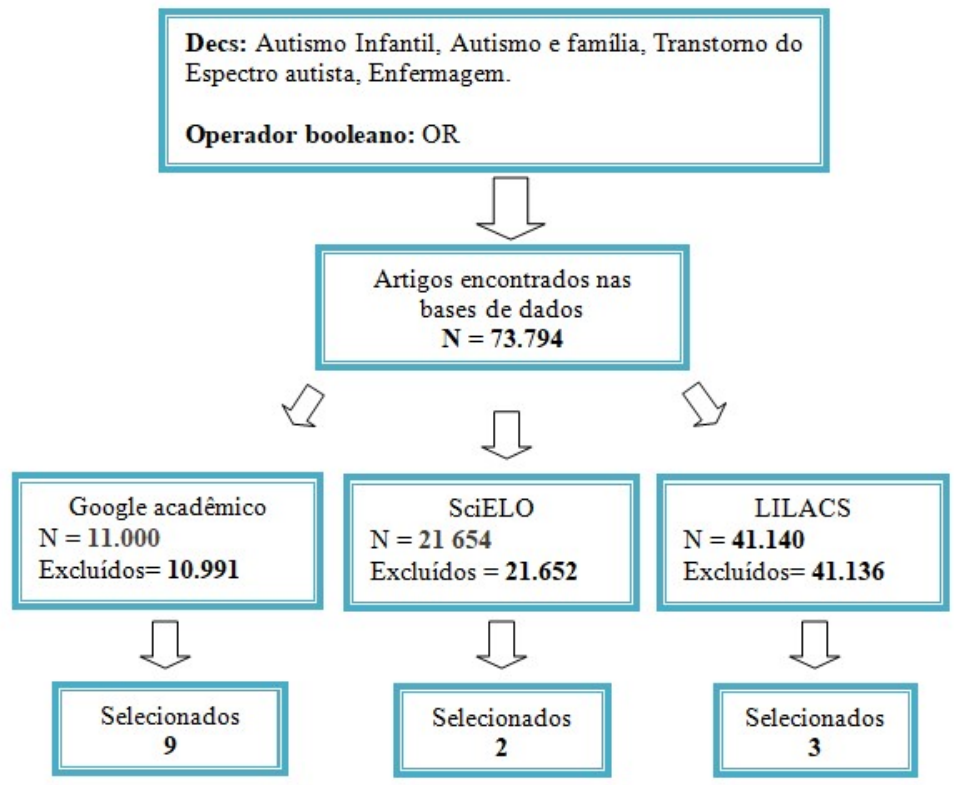

Figura 1: Quadro lógico da revisão sistemática.

Quando observado os cuidados de enfermagem apenas 5 artigos elencavam estes aspectos. Os sinais e sintomas que mais apareceram nos artigos escolhidos foram: dificuldades em interação e comunicação social, sensibilidade sensorial, déficit na coordenação motora e de atenção, dificuldade na realização de atividades simples do dia-a-dia.

Segundo os artigos os familiares desses portadores relatam choque, medo, choro, sentimento de incapacidade, ansiedade, raiva, ao receber o diagnóstico. Logo após, sentimentos de reorganização e aceitação começam a surgir, assim que o seu cotidiano começa a ser extremamente voltado aos cuidados da criança com transtorno do espectro autista.

Tabela 1: Publicações que apresentam os cuidados de enfermagem ao paciente portador de TEA e seus familiares, segundo Ano de publicação, Cuidados de enfermagem, Condutas e atitudes do profissional enfermeiro, Sinais e sintomas do portador de TEA segundo relatados nos artigos e Visão do familiar.

\begin{tabular}{|l|l|l|l|}
\hline $\begin{array}{c}\text { Ano de } \\
\text { publicação }\end{array}$ & \multicolumn{1}{|c|}{$\begin{array}{c}\text { Cuidados e Condutas de } \\
\text { enfermagem }\end{array}$} & $\begin{array}{l}\text { Sinais e sintomas do portador de } \\
\text { TEA segundo relatados nos artigos }\end{array}$ & \multicolumn{1}{c|}{ Visão do Familiar } \\
\hline \multirow{2}{*}{2001} & --- & $\begin{array}{l}\text { Síndrome comportamental com } \\
\text { etiologias múltiplas em } \\
\text { consequência de um distúrbio de } \\
\text { desenvolvimento, sendo } \\
\text { caracterizado por déficit na } \\
\text { interação social visualizado pela } \\
\text { inabilidade em relacionar-se com o } \\
\text { outro, usualmente combinado com } \\
\text { déficits de linguagem e alterações } \\
\text { de comportamento. }\end{array}$ & $\begin{array}{l}\text { Neste estudo as } \\
\text { famílias com pacientes autistas, são } \\
\text { significativamente dificultadoras da } \\
\text { saúde emocional dos membros do } \\
\text { grupo, com a doença crônica } \\
\text { tornando-se um sintoma que } \\
\text { acomete uma família de forma } \\
\text { permanente. Tal sintoma expressa- } \\
\text { se através das dificuldades } \\
\text { enfrentadas frente a papéis, } \\
\text { comunicação, liderança, } \\
\text { manifestação da agressividade e } \\
\text { afeição física. }\end{array}$ \\
\hline \multirow{2}{*}{2011} & $\begin{array}{l}\text { Atividades de vida diária como: } \\
\text { troca de fraldas, alimentação, } \\
\text { dependentes para higiene oral e }\end{array}$ & $\begin{array}{l}\text { Dificuldade ou inabilidade de } \\
\text { relacionamento social, na } \\
\text { comunicação e repertório }\end{array}$ & $\begin{array}{l}\text { "Meu filho está falando } \\
\text { corretamente o que quer comer" } \\
\text { (resultados obtidos através do PECS); }\end{array}$ \\
\hline
\end{tabular}




\begin{tabular}{|c|c|c|c|}
\hline & $\begin{array}{l}\text { banho. Todas as atividades de } \\
\text { Enfermagem seguem os passos do } \\
\text { Processo de Enfermagem } \\
\text { preconizados por Horta: histórico } \\
\text { (entrevista, exame físico e } \\
\text { psíquico); diagnóstico de } \\
\text { enfermagem; planejamento; } \\
\text { implementação e evolução de } \\
\text { enfermagem. }\end{array}$ & comportamental. & $\begin{array}{l}\text { "Meu filho hoje já não usa mais } \\
\text { fraldas" (resultados obtidos através } \\
\text { do treinamento de habilidades } \\
\text { básicas AVD); “Meu filho já consegue } \\
\text { esperar quando estamos em algum } \\
\text { lugar" (resultados obtidos através } \\
\text { das atividades realizadas em uma } \\
\text { mesa, a criança trabalhando } \\
\text { independentemente, através do } \\
\text { Método Teacch). }\end{array}$ \\
\hline 2011 & ---- & $\begin{array}{l}\text { Problemas sociais, de } \\
\text { comportamento e de linguagem. }\end{array}$ & $\begin{array}{l}\text { A mãe considerou que os pressionais } \\
\text { de saúde nunca valorizaram as } \\
\text { queixas, assim como sempre } \\
\text { encararam as suas opiniões e } \\
\text { indicações irrelevantes para os } \\
\text { tratamentos. }\end{array}$ \\
\hline 2015 & $\begin{array}{l}\text { O profissional enfermeiro pode } \\
\text { colaborar de forma positiva para o } \\
\text { diagnóstico e acompanhamento } \\
\text { do TA, através de observações } \\
\text { comportamentais de crianças, } \\
\text { mediante a consulta para analisar } \\
\text { o crescimento e o } \\
\text { desenvolvimento, como também, } \\
\text { podem auxiliar os progenitores } \\
\text { dando apoio e informando-os } \\
\text { quanto aos desafios e } \\
\text { procedimentos assistenciais que } \\
\text { os mesmos utilizarão no processo } \\
\text { de cuidar da criança com autismo. }\end{array}$ & $\begin{array}{l}\text { Afeta as áreas de desenvolvimento } \\
\text { psiconeurológico da criança, } \\
\text { comprometendo seu } \\
\text { desenvolvimento cognitivo, social e } \\
\text { comportamental, interferindo } \\
\text { diretamente no convívio e no } \\
\text { estabelecimento de relações sociais } \\
\text { com outras pessoas, dificultando } \\
\text { sua adaptação ao meio em que vive. }\end{array}$ & ---- \\
\hline 2016 & ---- & $\begin{array}{l}\text { Déficits de habilidades sociais, } \\
\text { déficits de habilidades } \\
\text { comunicativas (verbais e não } \\
\text { verbais) e presença de } \\
\text { comportamentos, interesses e/ou } \\
\text { atividades restritos, repetitivos e } \\
\text { estereotipados. }\end{array}$ & $\begin{array}{l}\text { O estágio inicial de luto é de choque, } \\
\text { acompanhado de choro, } \\
\text { manifestando sentimentos de } \\
\text { desamparo e ânsia por fugir; no } \\
\text { segundo estágio, há descrença e } \\
\text { negação da situação; no terceiro, há } \\
\text { tristeza e ansiedade manifestada por } \\
\text { muito choro e raiva; no quarto, há o } \\
\text { equilíbrio, caracterizado pela } \\
\text { admissão de que a condição existe; } \\
\text { por último, o estágio de } \\
\text { reorganização, mediante } \\
\text { reintegração e reconhecimento } \\
\text { familiar desse filho. }\end{array}$ \\
\hline 2016 & $\begin{array}{l}\text { Os profissionais em saúde devem } \\
\text { obter compreensão sobre o } \\
\text { autismo de maneira especializada } \\
\text { e profunda para que orientem a } \\
\text { família e a informem acerca da } \\
\text { síndrome. }\end{array}$ & $\begin{array}{l}\text { Algumas crianças ou adolescentes } \\
\text { com autismo possuem a fala e } \\
\text { inteligência bem desenvolvidas, } \\
\text { outras apresentam um retardo } \\
\text { mental ou relacionados ao } \\
\text { desenvolvimento da linguagem, } \\
\text { comprometendo assim a } \\
\text { comunicação. }\end{array}$ & $\begin{array}{l}\text { Ainda de acordo com a fala dos pais, } \\
\text { a exclusão é presente em seu } \\
\text { cotidiano, de maneiras distintas e de } \\
\text { acordo com cada realidade e cada } \\
\text { um deles junto a seus filhos, se sente } \\
\text { a margem de uma sociedade sem } \\
\text { informação sobre a síndrome e } \\
\text { preconceituosa. }\end{array}$ \\
\hline 2017 & $\begin{array}{l}\text { Exame psíquico, diagnóstico e } \\
\text { intervenções. } \\
\text { O enfermeiro responsável por } \\
\text { identificar os problemas que } \\
\text { acometem a criança, atuar na } \\
\text { elaboração de intervenções e } \\
\text { diagnósticos de enfermagem } \\
\text { voltados para a doença, } \\
\text { promovendo assim um melhora } \\
\text { na vida da criança e evitando a } \\
\text { progressão e os danos } \\
\text { ocasionados pela doença. }\end{array}$ & $\begin{array}{l}\text { Transtorno do desenvolvimento } \\
\text { caracterizado por prejuízos } \\
\text { precoces na socialização e } \\
\text { comunicação, bem como } \\
\text { comportamentos e interesses } \\
\text { restritos e estereotipados. }\end{array}$ & ---- \\
\hline 2018 & $\begin{array}{l}\text { No acompanhamento do } \\
\text { desenvolvimento infantil, o } \\
\text { enfermeiro tem a oportunidade }\end{array}$ & $\begin{array}{l}\text { Afeta áreas do } \\
\text { neurodesenvolvimento } \\
\text { responsáveis pela interação social, }\end{array}$ & ---- \\
\hline
\end{tabular}




\begin{tabular}{|c|c|c|c|}
\hline & $\begin{array}{l}\text { de identificar alterações } \\
\text { disfuncionais, o peso, a altura, a } \\
\text { amamentação, a alimentação, a } \\
\text { presença de comportamentos } \\
\text { inesperados, bem como avaliam } \\
\text { se as crianças sentam sem apoio, } \\
\text { se sustentam a cabeça no tempo } \\
\text { esperado, se observam pessoas } \\
\text { ao seu redor, se fazem contato } \\
\text { visual, se balbuciam alguma coisa, } \\
\text { e se transferem objetos de uma } \\
\text { mão para a outra. }\end{array}$ & comunicação e comportamento. & \\
\hline 2018 & ---- & $\begin{array}{l}\text { Altera a capacidade de interagir e } \\
\text { de se comunicar com o mundo, } \\
\text { apresentando dificuldades na } \\
\text { reciprocidade social. Além disso, } \\
\text { frequentemente, demonstram } \\
\text { comportamentos estereotipados ou } \\
\text { rígidos, podendo abanar mãos, } \\
\text { enfileirar objetos, aderir } \\
\text { excessivamente à rotina, resistir à } \\
\text { mudança, apresentar interesses } \\
\text { limitados e fixos, além de outros } \\
\text { sintomas. }\end{array}$ & $\begin{array}{l}\text { De acordo com os participantes, o } \\
\text { diagnóstico foi sentido como um } \\
\text { momento de desespero e tristeza, o } \\
\text { qual desencadeou dúvidas } \\
\text { relacionadas ao futuro da família e } \\
\text { da criança. Percebe-se que as } \\
\text { características do TEA expõem os } \\
\text { familiares ao luto pela perda da } \\
\text { criança saudável idealizada por eles. }\end{array}$ \\
\hline 2018 & ---- & $\begin{array}{l}\text { Déficits na comunicação social, na } \\
\text { interação, na sensibilidade } \\
\text { sensorial, coordenação motora e } \\
\text { níveis de atenção, com a presença } \\
\text { de complicações no que diz respeito } \\
\text { ao empenho e a realização de } \\
\text { atividades. }\end{array}$ & $\begin{array}{l}\text { A pesquisa findou com a verificação } \\
\text { de que a maioria dos cuidadores } \\
\text { relatou que seu cotidiano é } \\
\text { extremamente voltado aos cuidados } \\
\text { da criança/pessoa com transtorno do } \\
\text { espectro autista. }\end{array}$ \\
\hline 2018 & ---- & $\begin{array}{l}\text { Déficits persistentes na linguagem } \\
\text { receptiva e expressiva e na } \\
\text { interação social, com presença de } \\
\text { comportamentos restritivos e } \\
\text { repetitivos de atividades e } \\
\text { interesses. }\end{array}$ & $\begin{array}{l}\text { O estudo relata a dificuldade de pais } \\
\text { para inserir seus filhos no ensino } \\
\text { regular, já que a escola garante a } \\
\text { matrícula e prioriza o discurso da } \\
\text { aceitação à diversidade, porém, na } \\
\text { prática, não se modifica para } \\
\text { atender às singularidades da } \\
\text { aprendizagem e do desenvolvimento } \\
\text { desses alunos, faltando, inclusive, } \\
\text { preparo e auxílio para os } \\
\text { professores. }\end{array}$ \\
\hline 2019 & ---- & $\begin{array}{l}\text { Comunicação social e interação } \\
\text { social; e por padrões restritos e } \\
\text { repetitivos de comportamento, } \\
\text { interesses e atividades. }\end{array}$ & $\begin{array}{l}\text { Quanto às concepções sobre os } \\
\text { colegas da turma em geral, as } \\
\text { crianças dos dois CREI, nas duas } \\
\text { etapas do estudo, também referiram } \\
\text { adjetivos positivos - como bons, } \\
\text { legais e ótimos. Contudo, na etapa } \\
\text { final, apenas no CREI 1, algumas } \\
\text { crianças se referiram a seus colegas } \\
\text { por meio de adjetivos negativos, } \\
\text { como "ruins", por exemplo. }\end{array}$ \\
\hline 2019 & ---- & $\begin{array}{l}\text { Manifestações comportamentais } \\
\text { acompanhadas de déficits de } \\
\text { comunicação e interação social, } \\
\text { comportamentos repetitivos e } \\
\text { estereotipados. }\end{array}$ & $\begin{array}{l}\text { Os familiares apresentaram reações } \\
\text { diversas, como aceitação, } \\
\text { preocupação, sofrimento, negação, } \\
\text { sensação de impotência e previsão } \\
\text { de momentos turbulentos. De } \\
\text { acordo com os relatos, a rotina } \\
\text { familiar sofreu profundas mudanças } \\
\text { devido ao cuidado e atenção } \\
\text { dispensados à criança, dentre elas a } \\
\text { necessidade de renunciar às } \\
\text { atividades profissionais. }\end{array}$ \\
\hline 2019 & ---- & $\begin{array}{l}\text { Comportamento estereotipado e } \\
\text { interesses restritos, interação social } \\
\text { recíproca prejudicada e habilidades } \\
\text { de comunicação verbal e não verbal, }\end{array}$ & $\begin{array}{l}\text { A partir da análise dos fragmentos } \\
\text { narrativos que indicaram como o } \\
\text { nascimento do filho autista afetou a } \\
\text { vida dos pais e da família, foram }\end{array}$ \\
\hline
\end{tabular}




\begin{tabular}{|l|l|l|l|}
\hline & $\begin{array}{l}\text { Hiperatividade, comportamento } \\
\text { agressivo em relação a si ou aos } \\
\text { outros, incapacidade intelectual, } \\
\text { alterações sensoriais e distúrbios do } \\
\text { sono. }\end{array}$ & $\begin{array}{l}\text { identificadas cinco categorias: 1) } \\
\text { "Efeitos emocionais e relacionados à } \\
\text { saúde"; } 2 \text { ) “Efeitos na vida diária / } \\
\text { profissional e acadêmica"; 3) “Efeitos } \\
\text { na vida conjugal e / ou afetiva / } \\
\text { sexual”; } 4 \text { ) “Efeitos na vida social”; } \\
5 \text { ) "Estratégias de adaptação" } \\
\text { (apresentadas em conjunto com as } \\
\text { outras categorias). }\end{array}$ \\
\hline
\end{tabular}

Referente às potencialidades e dificuldades encontradas pelos profissionais enfermeiros descritas nas literaturas selecionadas, observa-se como potencialidades: a implementação da SAE e a elaboração de intervenções e diagnósticos de enfermagem voltados para os portadores de TEA, acompanhamento do profissional enfermeiro com esse portador, cuidados da enfermagem como: alimentação e higiene, no auxílio aos familiares desses portadores, Ihes apoiando e informando sobre a condição de seu filho e na identificação de alterações disfuncionais durante o exame físico. Já como dificuldades, foi elencada a falta de informações sobre o assunto, falta de contato com os pacientes com TEA, falta de capacitação e a falta de interesse pelo assunto (Tabela 2).

Tabela 2: Classificação das potencialidades e dificuldades encontrada na assistência de enfermagem ao portador de TEA e seus familiares, segundo a literatura analisadas.

\begin{tabular}{|l|l|}
\hline Potencialidades & Dificuldades \\
\hline - Colocação da SAE em prática. & - Falta de informações sobre o assunto. \\
\hline - Cuidados de enfermagem. & $\begin{array}{l}\text { - Falta de contato com os pacientes com } \\
\text { TEA. }\end{array}$ \\
\hline - Auxilio aos familiares dos portadores, como, apoio e informações. & - Falta de capacitação. \\
\hline $\begin{array}{l}\text { - Elaboração de intervenções e diagnósticos de enfermagem voltados para a a } \\
\text { síndrome. }\end{array}$ & - Falta de interesse pelo assunto. \\
\hline - Acompanhamento desse portador. & \\
\hline - Identificação de alterações disfuncionais. & \\
\hline
\end{tabular}

\section{DISCUSSÃO}

Segundos os manuais, as principais alterações do portador do autismo são nas áreas de relacionamento interpessoal e comunicativo, não interagir socialmente e nem verbalmente com as pessoas, também apresentando falta de apetite, falta de empatia, hiperfoco, dificuldades com mudanças, interpretação muito literal da linguagem, movimentos repetitivos, comportamentos estereotipias (FERNANDES et al., 2018).

Quando a família se depara com o diagnóstico de que seu filho (a) apresenta a síndrome, a família entra em choque, desespero, apresentando sentimento de incapacidade e dúvida, por estarem lidando com algo até então desconhecido, depois de terem digerido a situação, sentimentos de reorganização e aceitação começam a surgir, e a procura de ajuda profissional começa a ser prioridade. Os pais de crianças autistas têm o seu dia-a-dia completamente voltado aos cuidados do mesmo, com isso, esses pais relatam uma saúde mental abalada, pelo grande esforço físico e emocional que precisam ter para lidar com o portador. Ainda de acordo com os relatos dos pais, a exclusão é presente em seu cotidiano, que acabam se sentindo em uma sociedade sem informação sobre a síndrome e preconceituosa, visão essa que também foi apontada nos artigos desse estudo (CARVALHO et al., 2018; SPROVIERI et al., 2001; MAIA et al., 2016; BENTES, 2016). 
O enfermeiro como profissional possui papel fundamental no cuidado do autismo infantil, estando sempre atento aos sinais e sintomas que a criança venha apresentar, com suspeita da patologia, durante o exame físico, assim, identificando alguma alteração disfuncional, alertando os pais e o mais rápido possível prestando a assistência de enfermagem a essa família, Ihes dando apoio e informações sobre a síndrome, tirando as dúvidas dos mesmos e orientando como proceder daqui para frente (FERNANDES et al., 2018; SUDRÉ, 2018; NASCIMENTO et al., 2018; COSTA et al., 2017).

É competência do profissional enfermeiro, identificar alterações disfuncionais durante o exame físico do possível portador, acompanhar essa criança e a sua família, sempre orientado e informando os pais, implementar a SAE e elaborar intervenções e diagnósticos de enfermagem voltados para a síndrome, sempre seguindo as orientações que Ministério da saúde (MS) e a Organização Mundial da Saúde (OMS) exigem (FERNANDES et al., 2018; SUDRÉ, 2018; NASCIMENTO et al., 2018; COSTA et al., 2017).

Observou no presente estudo que a maioria dos artigos foram publicados nos de 2018 e 2019, possivelmente por ser um assunto novo para a área da enfermagem, pelo fato de ter poucos achados na literatura sobre a atuação do profissional enfermeiro, por muitas das vezes ser um assunto onde esses profissionais não demostram interesse em aprender, ou por não terem tanto contato com esses portadores, assim, não procurando realizar uma capacitação para que possam atender esse tipo de paciente de uma forma ampla.

Outra possibilidade de ter poucas publicações sobre a assistência de enfermagem ao autismo, o que também justifica o porquê essas publicações serem mais recentes, seria que segundo Souza (2019), estimase que exista mais de 2 milhões de portadores do autismo no Brasil, o que justifica um aumento constante da busca dos pais por ajuda profissional, tendo em vista que a lei que ampara os autistas chamada de "Política Nacional de Proteção dos Direitos da Pessoa com Transtorno do Espectro Autista", que foi criada em 2012, onde ela anuncia que os portadores do transtorno do espectro autista, tem os mesmos direitos que qualquer outro cidadão que apresenta necessidades especiais no Brasil, o que explica a busca maior recentemente.

A região Sudeste foi à região onde a maioria dos estudos analisados foram desenvolvidos. Uma hipótese para tal achado seria que a região sudeste é referência no tratamento de portadores do autismo, tendo como destaque o Instituto de Psiquiatria do Hospital das Clínicas da Faculdade de Medicina da USP, que tem como pilares a assistência ao portador, o ensino e formação de profissionais para atendimento psiquiátrico e a pesquisa de novos tratamentos.

Referente ao tipo de estudo, foram encontrados na maioria de cunho exploratório qualitativa, por estas pesquisas terem como objetivo, proporcionar maior familiaridade com o problema, com vistas a tomálo mais explícito ou a constituir hipóteses. Pode-se dizer que estas pesquisas têm como objetivo principal o aprimoramento de ideias ou a descoberta de intuições. Seu planejamento é, portanto, bastante flexível, de modo que possibilite a consideração dos mais variados aspectos relativos ao fato estudado. Na maioria dos casos, essas pesquisas envolvem: (a) levantamento bibliográfico; (b) entrevistas com pessoas que tiveram experiências práticas com o problema pesquisado; e (c) análise de exemplos que "estimulem a compreensão" (GIL, 2002). 


\section{CONCLUSÕES}

Esta pesquisa permitiu identificar os sinais e sintomas do autismo, como é a relação dos portadores com os seus familiares, como é feita a assistência de enfermagem quando se deparam com esse tipo de paciente e seus familiares e quais são as condutas tomadas por esses profissionais, em três bases de dados, com crianças de 18 meses a 10 anos, nos últimos 20 anos.

Os sinais e sintomas que mais se repetiram foram dificuldades na interação social e na comunicação, assim dificultando a afetividade familiar. Os familiares apresentam uma saúde mental abalada, pelo grande esforço que fazem para cuidar desses portadores, já que o seu cotidiano acaba girando em torno do autista.

Já referente às condutas dos enfermeiros que mais se sobressaíram nos artigos foram a identificação da síndrome, a informação e o apoio a família do possível portador, a aplicação da SAE e elaboração de intervenções e diagnósticos para o portador e o acompanhamento desse portador e da sua família, sempre lhes informando sobre a síndrome.

Foram encontradas poucas literaturas onde se falavam das condutas do profissional enfermeiro diante de pacientes com transtorno do espectro autista, apresentando como justificativa, a falta de contato com esse tipo de paciente, a falta de interesse desses profissionais o que consequentemente acaba ocorrendo a falta de uma capacitação.

Salienta-se a importância do profissional enfermeiro se capacitar e compreender melhor como atuar frente as síndromes que fazem parte do transtorno global do desenvolvimento, já que nos últimos anos a busca por ajuda profissional tem aumentado, o profissional enfermeiro necessita estar capacitado para poder atender de forma correta, eficaz, humanizada em com olhar holístico tanto para o cuidado devido ao paciente portador de TEA quando a família e cuidador, para que assim realize de forma efetiva o cuidar integral desses indivíduos.

\section{REFERÊNCIAS}

BENTES, C. C. A.; BARBOSA, D. C.; FONSECA, J. R. M.; BEZERRA, L. C.. A família no processo de inclusão social da criança e adolescente com autismo: Desafios na sociedade contemporânea. Intertem@s Social, v.11, n.11, 2016.

CARVALHO FILHA, F. S. S.; SILVA, H. M. C.; CASTRO, R. P.; MORAES FILHO, I. M.; NASCIMENTO, F.-L. S. C.. Coping e estresse familiar e enfrentamento na perspectiva do transtorno do espectro do autismo. Revista de Divulgação Científica Sena Aires, v.7, n.1, p.23-30, 2018.

COSTA, L. E.; ABREU, F. P.; SOUSA, C. B. C.; CORDEIRO, J. M. S.; AGUIAR, A. S. C.. Assistência de enfermagem a criança com transtorno do espectro autista: estudo de caso. Revista Join Br, 2017.

FERNANDES, A. F. F.; GALLETE, K. G. C.; GARCIA, C. D.. A importância do cuidado de enfermagem diante do paciente com espectro autista. Revista Terra \& Cultura: Cadernos de Ensino e Pesquisa, v.33, n.65, p.33-44, 2018.

GIL, A. C.. Como classificar as pesquisas. Como elaborar projetos de pesquisa, v.4, p.44-45, 2002.
MAIA, F. A.; ALMEIDA, M. T. C.; OLIVEIRA, L. M. M.; OLIVEIRA, S. L. N.; SAEGER, V. S. A.; OLIVEIRA, V. S. D.; SILVEIRA, M. F.. Importância do acolhimento de pais que tiveram diagnóstico do transtorno do espectro do autismo de um filho. Cadernos Saúde Coletiva, v.24, n.2, p.228-234, 2016. DOI: https://doi.org/10.1590/1414462X201600020282

NASCIMENTO, Y. C. M. L.; CASTRO, C. S. C.; LIMA, J. L. R.; ALBUQUERQUE, M. C. S.; BEZERRA, D. G.. Transtorno do espectro autista: detecção precoce pelo enfermeiro na estratégia saúde da família. Revista baiana de enfermagem, v.32, p.1-12. 2018. Dol: http://dx.doi.org/10.18471/rbe.v32.25425

NOGUEIRA, M. A. A.; RIO, M.; MOREIRA, S. C.. A família com criança autista: apoio de enfermagem. Revista Portuguesa de Enfermagem de Saúde Mental, n.5, p.16-21, 2011.

SERRA, D.. Autismo, família e inclusão. Polêm!ca, v.9, n.1, p.40-56, 2010. 
SOUZA, R. A.; SANTOS, J. A.; SOARES, S. A.. Uma reflexão sobre as políticas de atendimento para as pessoas com Transtorno do Espectro Autista. Cadernos UniFOA, v.14, n.40, p.95-105, 2019.

SPROVIERI, M. H. S.; ASSUMPÇÃO JUNIOR, F. B.. Dinâmica familiar de crianças autistas. Arquivos de Neuro-psiquiatria, v.59, n.2A, p.230-237, 2001.
SUDRÉ, R. C. R.; OLIVEIRA, R. F.; FAILE, P. G. S.; TEIXEIRA, M. B.. Assistência de enfermagem a crianças com Transtorno Global do Desenvolvimento (TGD): autismo. Arquivos Médicos dos Hospitais e da Faculdade de Ciências Médicas da Santa Casa de São Paulo, v.56, n.2, p.102-106, 2018.

ZANON, R. B.; BACKES, B.; BOSA, C. A.. Identificação dos primeiros sintomas do autismo pelos pais. Psicologia: Teoria e Pesquisa, v.30, n.1, p.25-33, 2014.

A CBPC - Companhia Brasileira de Produção Científica (CNPJ: 11.221.422/0001-03) detém os direitos materiais desta publicação. Os direitos referem-se à publicação do trabalho em qualquer parte do mundo, incluindo os direitos às renovações, expansões e disseminações da contribuição, bem como outros direitos subsidiários. Todos os trabalhos publicados eletronicamente poderão posteriormente ser publicados em coletâneas impressas sob coordenação da Sustenere Publishing, da Companhia Brasileira de Produção Científica e seus parceiros autorizados. Os (as) autores (as) preservam os direitos autorais, mas não têm permissão para a publicação da contribuição em outro meio, impresso ou digital, em português ou em tradução. 